\title{
Emerging Agents for the Treatment of Advanced, Imatinib- Resistant Gastrointestinal Stromal Tumors: Current Status and Future Directions
}

\author{
Sebastian Bauer ${ }^{1,2} \cdot$ Heikki Joensuu ${ }^{3}$
}

Published online: 18 July 2015

(c) The Author(s) 2015. This article is published with open access at Springerlink.com

\begin{abstract}
Imatinib is strongly positioned as the recommended first-line agent for most patients with advanced gastrointestinal stromal tumor (GIST) due to its good efficacy and tolerability. Imatinib-resistant advanced GIST continues to pose a therapeutic challenge, likely due to the frequent presence of multiple mutations that confer drug resistance. Sunitinib and regorafenib are approved as second- and third-line agents, respectively, for patients whose GIST does not respond to imatinib or who do not tolerate imatinib, and their use is supported by large randomized trials. ATP-mimetic tyrosine kinase inhibitors provide clinical benefit even in heavily pretreated GIST suggesting that oncogenic dependency on KIT frequently persists. Several potentially useful tyrosine kinase inhibitors with distinct inhibitory profiles against both KIT ATP-binding domain and activation loop mutations have not yet been fully evaluated. Agents that have been found promising in preclinical models and early clinical trials include small molecule KIT and PDGFRA mutation-specific inhibitors, heat shock protein inhibitors, histone deacetylase inhibitors, allosteric KIT inhibitors, KIT and PDGFRA signaling pathway inhibitors, and immunological approaches including antibody-drug conjugates. Concomitant or
\end{abstract}

Heikki Joensuu

heikki.joensuu@hus.fi

1 Sarcoma Center, West German Cancer Center, University Hospital Essen, University Duisburg-Essen, Essen, Germany

2 German Cancer Consortium (DKTK), 69120 Heidelberg, Germany

3 Department of Oncology, Helsinki University Hospital and University of Helsinki, Haartmaninkatu 4, 00029 Helsinki, Finland sequential administration of tyrosine kinase inhibitors with KIT signaling pathway inhibitors require further evaluation, as well as rotation of tyrosine kinase inhibitors as a means to suppress drug-resistant cell clones.

\section{Key Points}

Mutated KIT kinases that confer drug resistance emerge frequently in patients with advanced GIST treated with imatinib.

Besides ATP-mimetic tyrosine kinase inhibitors many other agents with a different mechanism of action are efficacious in the treatment of patients with advanced GIST.

Concomitant or sequential administration of agents with different mechanisms of action may become a novel approach to treat advanced GIST.

\section{Introduction}

Gastrointestinal stromal tumor (GIST) is one of the most common types of sarcoma [1]. Small $(<1 \mathrm{~cm})$ GISTs ("micro-GISTs") are highly prevalent $(\sim 20 \%)$ in the general population aged over 50 years $[2,3]$, but these lesions have little or no malignant potential. Excluding micro-GISTs, the annual incidence of GIST is about $1 / 100,000$. Approximately $40 \%$ of patients will eventually have metastases after macroscopically complete surgery [4]. The median overall survival for patients with 
metastatic GIST was $12-18$ months before the introduction of imatinib [5].

Approximately $90 \%$ of metastatic GISTs harbor an activating mutation in the genes that encode KIT or platelet-derived growth factor- $\alpha$ (PDGFRA) receptor tyrosine kinases [6, 7]. Mutations are usually located in KIT exon 11 ( $\sim 70 \%)$, KIT exon $9(\sim 10 \%)$, or PDGFRA exons 12 or $18(\sim 10 \%)$. Mutations in other exons are infrequent in patients who have not been treated with tyrosine kinase inhibitors (TKIs) [8], and 5-10\% of GISTs do not harbor KIT or PDGFRA mutation (frequently referred to as "wildtype GISTs").

Conventional chemotherapy agents have little activity against GIST. During the past 15 years TKIs have transformed the treatment landscape in an unprecedented way. Several TKIs yield durable responses in patients with advanced GIST, and adjuvant imatinib improves recurrence-free survival [9, 10] and likely overall survival [10] when administered to GIST patients after surgery. Although the treatment of GIST with TKIs is one of the most compelling success stories in the recent history of medicine, a major challenge is the eventual emergence of drug resistance in advanced GIST. We review here the experimental agents studied to treat imatinib-resistant advanced GIST.

\section{Approved Agents}

\subsection{Imatinib}

Imatinib has been considered the standard first-line agent since its approval in 2002. It is an inhibitor of a few kinases including KIT, PDGFRA, ABL, Fms-like tyrosine kinase-3 (FLT3), and colony stimulating factor-1 receptor (CSF1R), and yields durable responses or stabilized disease (SD) in approximately $85 \%$ of the patients $[11,12]$.

Two randomized phase III trials that compared an imatinib daily dose of 400 to $800 \mathrm{mg}$ identified the 400-mg dose as the standard dose for patients with a KIT exon 11 mutation [13, 14]. In a retrospective subgroup analysis, patients with a KIT exon 9 mutation had longer progression-free survival (PFS) on the 800-mg dose as compared with the 400-mg dose [15]. PDGFRA substitution mutations at codon D842 (usually D842V) lead to imatinibresistant mutant kinases [16]. Mutational testing for $K I T$ and PDGFRA is therefore considered mandatory in the treatment planning [17].

Most patients with advanced GIST are not cured with imatinib. The median PFS is 2-3 years [18], but a minority remain progression-free for $\geq 10$ years after starting imatinib [19]. Patients are treated with continuous imatinib as discontinuation in responding patients is usually associated with rapid progression [20]. In one trial patients whose GIST had progressed on at least imatinib and sunitinib were randomly assigned to either imatinib re-challenge or placebo. The median PFS was 1.8 months on imatinib and 0.9 months on placebo [21]. Despite survival not improving, these findings suggest a modest benefit from imatinib, even as "last-line" therapy.

\subsection{Sunitinib}

Like imatinib, sunitinib binds to the ATP-binding pocket of the KIT and PDGFRA kinases. Sunitinib has different binding characteristics from imatinib and it also efficiently inhibits the vascular endothelial growth factor receptor (VEGFR) and RET tyrosine kinases.

Sunitinib was approved in 2006 for patients whose GIST has progressed on imatinib or who do not tolerate imatinib based on the results of a placebo-controlled trial [22]. In this study with 312 patients sunitinib was administered at a dose of $50 \mathrm{mg} /$ day for 4 weeks followed by a break of 2 weeks before the next cycle. The median PFS was 6.3 and 1.5 months in the sunitinib and placebo groups, respectively [hazard ratio (HR) $0.33, p<0.0001$ ), the partial response (PR) rates were 7 and $0 \%$, and the rates of stabilized disease (SD) 58 and $48 \%$. Cross-over to the sunitinib group was allowed, but despite this, overall survival was superior in the sunitinib group. The most frequent adverse effects were anemia, neutropenia, fatigue, diarrhea, skin discoloration, nausea, and anorexia. Sunitinib treatment is also frequently associated with hand-foot syndrome and occasionally hypothyreosis [23]. Administration at a continuous daily dose of $37.5 \mathrm{mg}$ is considered an alternative dosing schedule [24]. Despite these convincing results, the clinical benefits of secondline sunitinib remain moderate as compared with the substantial benefits obtained with imatinib in a first-line setting.

\subsection{Regorafenib}

Regorafenib is an oral TKI that inhibits multiple kinases involved in oncogenesis (KIT, PDGFRA, RET, RAF1, BRAF), angiogenesis (VEGFR1-3, TIE2), and the tumor microenvironment (fibroblast growth factor receptor, FGFR). Regorafenib was approved in 2013 for the treatment of GIST patients who no longer respond to imatinib and sunitinib based on a placebo-controlled, randomized phase III trial (GRID) [25]. In GRID, 199 such patients were allocated to regorafenib $160 \mathrm{mg} /$ day or matching placebo (3 weeks on/1 week off) until disease progression. The median PFS was 4.8 months on regorafenib and 0.9 months on placebo (HR $0.27, p<0.0001)$. Six $(4.5 \%)$ and one $(1.5 \%)$ of the patients assigned to regorafenib and 
placebo had PR, respectively, and 71.4 and $33.3 \%$ had SD. Drug-related grade 3 adverse events were frequent in the regorafenib group as compared to placebo (58 vs. $8 \%$ ), with hand-foot skin reaction, hypertension, and diarrhea being most often recorded.

Sunitinib and regorafenib have a less favorable side effect profile compared to imatinib, which is likely associated with their broader kinase inhibition spectrum. Handfoot syndrome tends to occur earlier with regorafenib than with sunitinib and is generally more severe. Regorafenib has significant liver toxicity, and liver function tests are recommended before initiation of regorafenib and at least every 2 weeks during the first 2 months on therapy [26]. The benefit of VEGFR inhibition remains undefined in GIST.

\section{Imatinib Resistance}

Secondary KIT mutations are the dominant mechanism for imatinib resistance $[27,28]$. They occur frequently either in the kinase ATP-binding domain (encoded by exons 13 and 14) or in the activation loop (a-loop, encoded by exon 17), and typically affect the key amino acids that interact with imatinib binding to the kinase. Mutations in the a-loop shift the equilibrium towards the active kinase conformation, while imatinib and sunitinib bind to the inactive conformation [29].

In a mutagenesis screen of cells driven by mutant KIT proteins, sunitinib effectively suppressed cells with KIT exon 13 (V654A) or exon 14 resistance mutations (T670I), but not exon 17 mutant kinases [30]. These results are compatible with findings from a clinical trial in which sunitinib had substantial activity against GISTs with secondary KIT exon 13 mutations [31]. In contrast, regorafenib shows higher potency for KIT exon 17 mutations, but is less potent for the ATP-binding domain affecting mutations. Imatinib-resistant disease frequently harbors several resistance mutations, sometimes even within a single metastasis [28, 32, 33].

The rare alternative mechanisms that may cause imatinib resistance include KIT amplification and loss of tumor KIT expression [27]. Alternative signaling pathways may supplant KIT as the oncogenic driver, but have not been confirmed in patients. Notably, dysregulation of the phosphatidylinositide 3-kinases (PI3K)/AKT pathway by $P I 3 K$-mutations or aberrations that cause loss of the phosphatase and tensin homolog (PTEN) function, or mutations of BRAF, KRAS, or HRAS that activate the RAS/RAF/MEK pathway, have been detected in single cases, but their overall role in drug resistance is unclear $[34,35]$.

\section{Investigational Agents}

Many investigational agents are potent KIT and PDGFRA inhibitors, and therefore potentially active against GIST.

\subsection{ATP Mimetics}

ATP mimetics are orally administered small molecule agents that bind to the target kinase ATP-binding pocket and compete with ATP for binding (Table 1).

\subsubsection{Nilotinib}

Nilotinib has been evaluated in randomized trials [36, 37] and cohort studies $[38,39]$. In a randomized study carried out in a first-line setting, 644 patients who had received no systemic antineoplastic therapy or who had GIST recurrence $\geq 6$ months after discontinuing adjuvant imatinib received either nilotinib $400 \mathrm{mg}$ twice daily or imatinib $400 \mathrm{mg}$ once daily [37]. Accrual was stopped early after crossing the futility boundary, and both PFS and overall survival significantly favored imatinib. Somewhat unexpectedly, patients treated with imatinib had better PFS in the subgroup with KIT exon 9 mutation, but not among patients with exon 11 mutation.

Nilotinib was compared to best supportive care (BSC) or with the physician's choice in a randomized trial with 248 patients who had progressed on imatinib and sunitinib [36]. Most control group patients received either imatinib or sunitinib in addition to BSC. No PFS difference emerged at a blinded central radiology review between the groups.

The development of nilotinib in the treatment of GIST was halted based on these results, but since nilotinib is well tolerated, it could have a niche in the treatment of patients who do not tolerate imatinib and whose GIST harbors KIT exon 11 mutation.

\subsubsection{Masitinib}

Masitinib is approved for the treatment of mastocytosis in dogs. In a phase II trial where 30 imatinib-naïve patients received masitinib $7.5 \mathrm{mg} / \mathrm{kg} /$ day, one patient had complete response (CR), 15 had PR, $13 \mathrm{SD}$, and one disease progression as the best response, and the median PFS was 41.3 months [40]. These efficacy results resemble those obtained with imatinib. The most frequent grade $3 / 4$ toxicities were skin rash $(10 \%)$ and neutropenia $(7 \%)$.

In a small randomized, open-label trial 23 patients who had progressed on imatinib were assigned to $12 \mathrm{mg} / \mathrm{kg} /$ day of masitinib and 21 comparable patients to sunitinib [41]. The median PFS was relatively short in the masitinib group (3.7 months), but overall survival favored masitinib to 


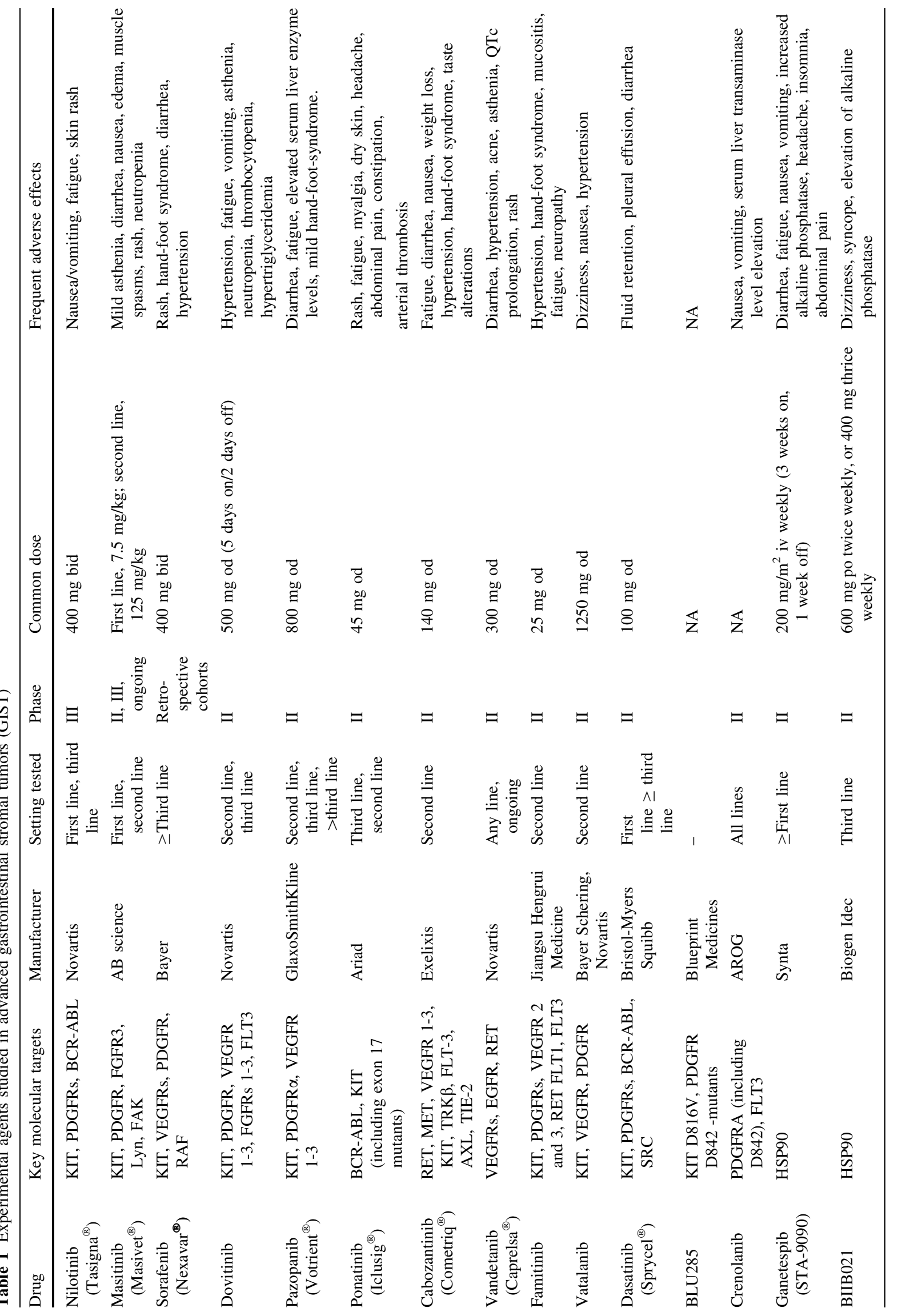




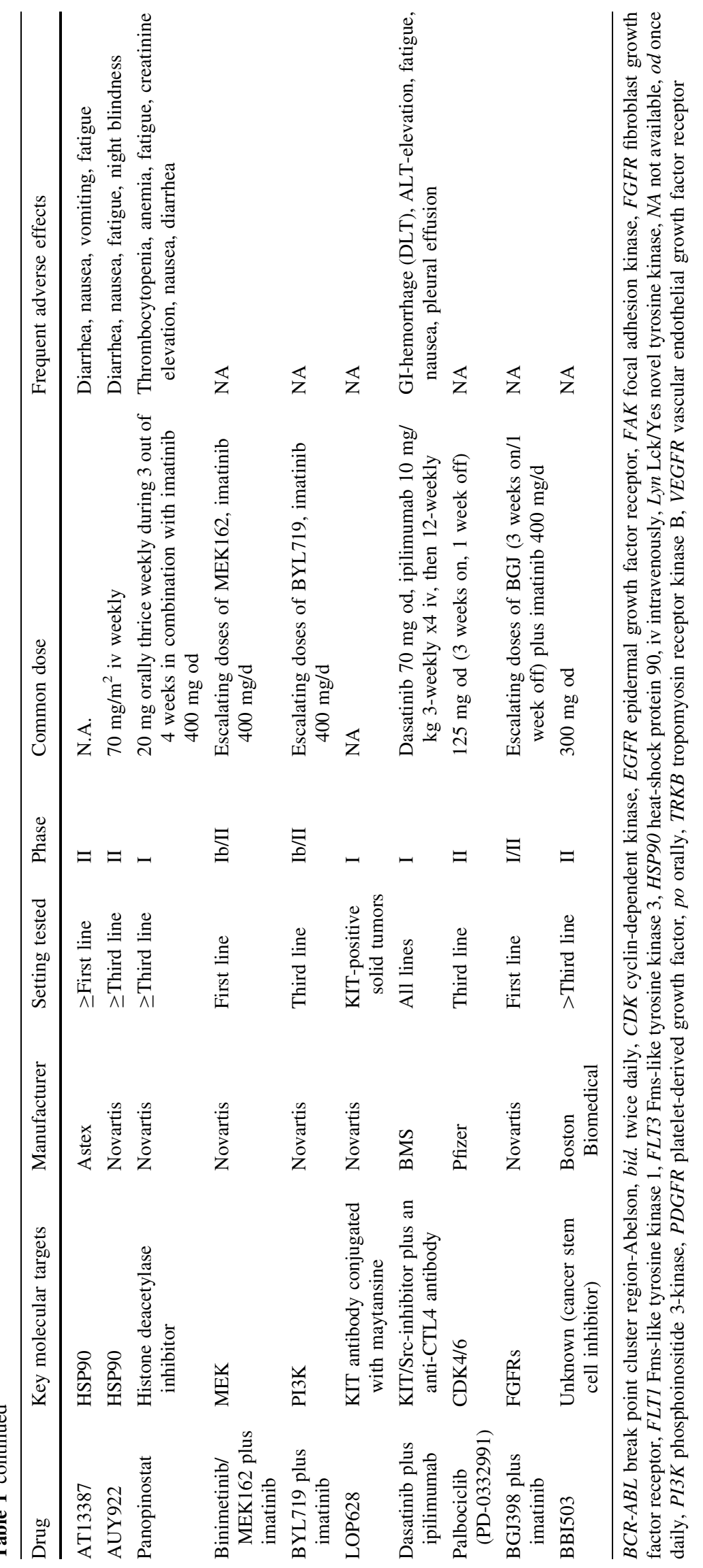


sunitinib after allowing post-progression administration of sunitinib in the masitinib group. Masitinib was better tolerated. These results warrant confirmation in the ongoing phase III trials (NCT00812240 and NCT01694277).

\subsubsection{Sorafenib}

Sorafenib resembles regorafenib in structure and in the kinome inhibition spectrum. Sorafenib is approved for the treatment for unresectable hepatocellular carcinoma, advanced renal cell carcinoma, and differentiated thyroid cancer. In vitro, sorafenib inhibits imatinib-resistant kinases with mutations in the KIT ATP-binding pocket and in the activation loop, with the exception of kinases resulting from substitutions at KIT codon D816 or PDGFRA codon 842 [42].

In a retrospective cohort study with 117 evaluable patients whose GIST had progressed on imatinib and sunitinib, and who were treated with sorafenib $400 \mathrm{mg}$ twice daily, $12(10 \%)$ patients responded and $70(60 \%)$ had SD. The median PFS was 6.4 months [43]. Sorafenib was moderately well tolerated, with skin rash, hand-foot syndrome, and diarrhea being the most frequent adverse effects.

In another retrospective study, six $(19 \%)$ patients responded and $14(44 \%)$ had SD in a cohort of 32 patients whose GIST had progressed on imatinib, sunitinib, and nilotinib [44]. These and further data [45] suggest that the efficacy of sorafenib might be comparable to that of regorafenib in the treatment GIST resistant to imatinib and sunitinib.

\subsubsection{Dovitinib}

The Korean GIST group conducted a study that evaluated dovitinib among 30 patients whose disease had progressed at least on imatinib and sunitinib, and found a disease control rate of $13 \%$ at 24 weeks after treatment initiation and a median PFS of 3.6 months [46].

In another study in 38 patients who had progressed on imatinib or who were intolerant to imatinib, two (5\%) patients had PR with dovitinib and 16 (42\%) SD. The median PFS was 4.6 months [47]. The most frequent grade 3 side effects were hypertension (18\%), fatigue $(12 \%)$, vomiting $(10 \%)$, and elevated blood triglyceride and $\gamma$ glutamyltransferase levels. Dovitinib may not be superior to sunitinib or regorafenib, but careful data evaluation might identify subgroups of patients who benefit from dovitinib.

\subsubsection{Pazopanib}

Pazopanib is approved for the treatment of renal cell cancer and soft tissue sarcomas. The $\mathrm{IC}_{50}$ value for inhibition of wild-type KIT was $74 \mathrm{nM}$ in in vitro kinase assays [48], but little is known about its activity on KIT drug resistance mutations.

In a phase II study $12(48 \%)$ out of the 25 patients whose GIST had progressed on at least imatinib and sunitinib had SD and the median PFS was 1.9 months [49].

The randomized phase II PAZOGIST trial compared pazopanib plus BSC with BSC alone among 81 patients whose GIST was resistant to imatinib and sunitinib, or who did not tolerate these agents [50]. The 4-month PFS rate favored pazopanib plus BSC over BSC alone ( 45 vs. $18 \%$, respectively; $p=0.03$ ). Of the 76 patients who were treated with pazopanib (including 36 patients who crossed over from BSC to pazopanib after progression), $72 \%$ had $\geq$ grade 3 adverse events (37\% had hypertension). These data do not suggest a higher activity as compared with regorafenib, but the toxicity profile of pazopanib could be more favorable.

\subsubsection{Ponatinib}

Ponatinib is highly active in heavily pre-treated patients for Philadelphia-positive leukemia, and exhibits a pan-BCRABL inhibitory profile in vitro with no single mutation conferring ponatinib resistance [51]. Ponatinib is one of the few ATP-competitive KIT-inhibitors that has been tested against a large panel of mutant KIT variants [30]. In a mutagenesis screen $40 \mathrm{nmol} / \mathrm{L}$ of ponatinib suppressed the growth of all KIT secondary mutants except V654A, which was suppressed at $80 \mathrm{nmol} / \mathrm{L}$. Ponatinib shows high activity against KIT exon 17 mutants, and unlike the approved KIT inhibitors, it is active against the KIT exon 17 D816 mutant kinases [30].

The preliminary results from a non-randomized phase II trial that evaluated ponatinib at a dose of $45 \mathrm{mg} /$ day in heavily treated GIST patients ( $74 \%$ had $\geq 4$ prior agents) the clinical benefit rate (CR, PR, or $\mathrm{SD} \geq 16$ weeks) was $55 \%$ in patients with primary KIT exon 11 mutation, but responses were also observed with the 30-mg dose [30, 52]. The most common side effects were skin rash $(54 \%)$, fatigue $(46 \%)$, myalgia (46\%), dry skin $(40 \%)$, and headache $(40 \%)$. Ponatinib is only infrequently associated with hand-foot syndrome or mucositis. No serious thromboembolic events were observed during the short followup, but $11.8 \%$ of the patients with BCR-ABL-driven leukemia had serious arterial thrombotic events that accumulated over a period of 24 months.

The risk of thromboembolic events may be dose-dependent, and the ponatinib blood maximum concentrations with the $15 \mathrm{mg} /$ day dose and the trough concentrations with the $30 \mathrm{mg} /$ day dose exceeded the $40 \mathrm{nM} / \mathrm{L}$ concentration that is required to suppress most imatinib-resistant KIT clones [53]. A phase II trial (POETIG) will evaluate ponatinib at a dose of $30 \mathrm{mg} /$ day in patients whose GIST is resistant to imatinib. 


\subsubsection{Other Tyrosine Kinase Inhibitors}

In a phase I study evaluating cabozantinib, four pretreated Japanese patients had SD lasting for 6-20 months [54]. The CABO-GIST study (NCT02216578) aims to evaluate cabozantinib in a larger patient cohort.

Vandetanib is approved for the treatment medullary thyroid cancer [55]. It is being investigated in a phase II trial in pediatric and adult patients with GIST who lack KIT and PDGFRA mutations (NCT02015065).

Famitinib induced PR in one of the two patients with treatment-naïve GIST included in a phase I study [56], and is being investigated as second-line treatment of advanced GIST (NCT02336724). Side effects included hypertension, hand-foot syndrome, mucositis, fatigue, and neuropathy.

In a phase II trial with 45 patients whose GIST was resistant to imatinib or to both imatinib and sunitinib, two (4\%) patients treated with vatalanib had confirmed PR and further $16(36 \%)$ had SD lasting for $\geq 6$ months (median 12.5 months) [57]. Vatalanib was well tolerated, with hypertension ( $29 \%$ ), nausea ( $29 \%)$, and dizziness (24\%) being the most common side effects (usually grade 1 or 2 ). Vatalanib is not being tested further in clinical trials.

Dasatinib is a potent inhibitor of BCR-ABL and the SRC-family kinases, and it also inhibits KIT and the PDGFRs [58]. Dasatinib is approved for the treatment of chronic myeloid leukemia. In a phase II study where TKInaïve GIST patients were treated with dasatinib $70 \mathrm{mg}$ twice daily, $31(74 \%)$ of the 42 eligible patients had metabolic response in fluorodeoxyglucose (FDG)-PET performed 4 weeks after dasatinib initiation [59]. The median PFS of 13.6 months achieved appears short in this setting. Adverse effects were most frequently gastrointestinal or pulmonary (grade 3, $48 \%$; grade 4, $5 \%$ ). Similarly, in another series where all patients had imatinibresistant GIST and most also sunitinib-resistant disease, the median PFS was only 2.0 months [60].

\subsubsection{Mutation-Specific Inhibitor}

BLU285 is a mutation-specific inhibitor of KIT D816V and PDGFRA D842V mutated kinases that are resistant to most TKIs. Preclinical data suggest a favorable toxicity profile, but clinical trials are pending [61]. BLU285 has a very narrow inhibition profile, and might therefore become a candidate for combination trials.

\subsubsection{PDGFRA-Targeted Agents}

Crenolanib is an oral small-molecule inhibitor of FLT3 and the PDGFRs (including D842V-mutated kinase) [62]. Metastatic PDGFRA-mutant GIST is exceedingly rare, and in a phase II trial with seven patients, one had an objective response and three had SD [63]. In a trial that accrued leukemia patients, the most common side effects were fatigue, nausea, and vomiting [64]. A clinical trial investigating olaratumab, an anti-PDGFRA antibody, was terminated prematurely due to lack of efficacy.

\subsection{Other Targeted Agents}

\subsubsection{Heat Shock Protein 90 (HSP90) Inhibitors}

HSP90 chaperone protein stabilizes and enhances conformational maturation of many proteins [65] including KIT and PDGFRA. As ATP hydrolysis is required, HSP90 becomes pharmacologically targetable [66]. HSP90 inhibition eventually results in proteasomal degradation of the client proteins. One of the first HSP90-inhibitors, the geldanamycin analogue 17-AAG, inhibited KIT regardless of the type of imatinib-resistance mutation [67]. The HSP90 co-chaperone cdc37 ranked the highest in a genome-wide functional screen on two KIT-mutant cell lines, suggesting that the chaperones are relevant in maintaining KIT signaling [68].

Retaspimycin (IPI-504), a 17-AAG derivative, had promising efficacy in a phase I trial [69], but a subsequent randomized phase III trial performed in a third-line setting was terminated early due to higher mortality in the retaspimycin group.

Ganetespib was generally well tolerated in a cohort of 23 GIST patients, but no responses were obtained and the $12(52 \%)$ SDs achieved were usually short [70]. BIIB021 was also well tolerated, but had limited clinical activity [71].

AT13387 showed promising preclinical activity in GIST [72], and seven GIST patients were treated in the first-inhuman phase I trial. One patient had PR lasting for 10 months, and three had SD for up to 8 months [73]. This prompted initiation of a phase II trial in GIST (NCT01294202), but the results are pending. Similarly, a small molecule inhibitor, AUY922, had activity in preclinical GIST models, but the results from a phase II trial conducted in a patient population with imatinib- and sunitinib-resistant GIST are not yet available (NCT01404650).

\subsubsection{Histone Deacetylase Inhibitors (HDACIs)}

Acetylation of the lysine residues of the core histone proteins leads to a relaxed chromatin structure enabling transcription [74]. HDACIs have selectivity for cell cycle inhibitory genes [75]. In addition, many non-histone proteins important for oncogenesis are targets for acetylation and deacetylation (e.g. p53) [76].

HDACI treatment results in transcriptional downregulation and proteasomal degradation of KIT, and additive 
effects are found in combination with imatinib both in vitro and in vivo [77, 78]. This prompted a phase I trial with panobinostat, a third-generation pan-HDACI, in combination with imatinib $400 \mathrm{mg} /$ day in a heavily pretreated GIST patient population. The maximum tolerated dose in the combination was $20 \mathrm{mg}$ panobinostat given orally three times weekly during three out of every four weeks, which was only moderately well tolerated with substantial hematological toxicity (thrombocytopenia) [79]. One out of the 11 evaluable patients showed metabolic PR, seven were metabolically stable for $\geq 3$ weeks, and three progressed. The longest treatment duration was 17 weeks. The panobinostat administration schedule may need further refinement, and other combinations warrant evaluation.

\subsubsection{Allosteric KIT Inhibitors}

In addition to the ATP-binding pocket KIT has another pocket, an interior pocket located between the $\mathrm{N}$ - and $\mathrm{C}$-lobes of the kinase. There are two pendant ligands that compete for occupancy of this "switch pocket" [80, 81]. Mutation or deletion of the inhibitory switch ligand renders KIT constitutively active. Novel KIT inhibitors that target the switch pocket were recently developed (DP-2976, DP3636, and DP-4444). They are highly potent against several imatinib and sunitinib-resistant GIST cell lines [80, 82]. It is unclear whether these compounds are candidates for clinical trials, but the rationale for their use is strong. While the ATP-binding pockets are highly conserved throughout the kinome, the allosteric sites have greater structural diversity, and compounds targeting these sites may inhibit kinase activity with a high selectivity [80].

\subsection{Inhibition of Signaling Pathways}

The oncogenic KIT signaling is mainly relayed via the PI3K/mammalian target of rapamycin (mTOR) and the RAS/RAF/MEK/MAPK pathways in GISTs with or without secondary resistance mutations, and inhibition of both PI3K and MEK results in strong proapoptotic and antiproliferative effects in vitro and in vivo [83-85]. Besides KIT, molecular aberrations in other key proteins may activate these pathways, such as aberrations in PTEN, PI3K, RAF, RAS, or NF1 [35, 86-88].

The combination of everolimus, an mTOR inhibitor, and imatinib was one of the first combinations of targeted agents studied in GIST [89]. When patients refractory to imatinib or to imatinib and sunitinib were treated with everolimus and imatinib 600-800 mg/day, the combination was well tolerated, with diarrhea, nausea, fatigue, and anemia as the most common adverse events. The progression-free rate was $37 \% 4$ months after treatment initiation and one patient had PR, but the median PFS of 3.5 months achieved was relatively short. No follow-up trial was initiated, but this combination might qualify for testing with a PI3K inhibitor in imatinib-resistant disease.

Ongoing trials are investigating the combination of imatinib plus a MEK inhibitor (MEK162/binimetinib) as first-line treatment (NCT01991379), and imatinib plus a PI3K inhibitor (BYL719) as third-line treatment (NCT01735968). In a phase Ib/II trial in a heavily pretreated patient population, nine out of the 15 evaluable patients treated with binimetinib plus imatinib had stable disease at 8 weeks on treatment, and five $(33 \%)$ had a partial response according to the Choi criteria [90].

\subsection{Immunological Approaches}

LOP628 is a conjugate consisting of an anti-KIT humanized $\mathrm{IgG} 1 / \kappa$ antibody linked with a maytansine payload. As this approach is based on KIT expression and not on the type of KIT mutation, it might have efficacy not only against GISTs refractory to TKIs but also for patients with wild-type GIST.

In a study investigating the combination of dasatinib and ipilimumab (NCT01643278), an antibody targeting the immune checkpoint protein cytotoxic T-lymphocyte-associated protein-4 (CTLA4), one out of the eight patients treated had durable SD for 59+ weeks [91]. Few data are available about the expression of other checkpoint proteins such as PDL1, PDL2, or LAG3 in GIST. The study evaluating pembrolizumab, an antibody that targets the programmed cell death 1 (PD-1) receptor, in advanced sarcomas (NCT02406781) is not yet recruiting patients. Some studies suggest a role for the natural killer cells in the immune control of GIST [92, 93].

\subsection{Other Targets}

$C D K N 2 A$ loss is a common genetic aberration in metastatic GIST [94], and several studies show an association between low tumor p16 ${ }^{\text {ink4 }}$ (the gene product of $C D K N 2 A$ ) and frequent response to cyclin-dependent kinase (CDK) 4/6 inhibitors [95]. Based on such observations, one study is investigating palbociclib (a CDK 4/6 inhibitor) in patients whose GIST is refractory to imatinib and sunitinib (NCT01907607).

FGFRs may mediate resistance to imatinib in GIST [96, 97]. A current trial evaluates a pan-FGFR inhibitor BGJ398 in combination with imatinib in untreated advanced GIST (NCT02257541), but no results are yet available.

Inhibition of the mouse double minute 2 homolog (MDM2) enhanced the pro-apoptotic effects of KIT inhibitors in GIST cell lines [98]. MDM2 inhibitors are 
currently being tested in phase I trials, but not at present in GIST. A trial with BBI503, an orally administered multikinase inhibitor with putative activity against cancer stem cells, is being planned as the treatment for advanced GIST (NCT02232620).

\section{Future Prospects}

A large tumor load is a negative prognostic factor for overall survival [99]. Minimizing the tumor load by metastasis surgery might postpone emergence of drug-resistant mutations [100], but this hypothesis remains unproven. Plasma DNA sequencing might help in screening for pre-existing or emerging resistant subclones.

Alternation of TKIs with different kinome inhibitory profiles may be feasible and might suppress resistant clones. It is important to investigate drug combinations that include a mutation-specific inhibitor or an agent that inhibits a KIT-depending signaling cascade, and the novel immune function-modifying agents also warrant investigation.

\section{Conclusions}

Imatinib is strongly positioned as the recommended firstline agent for most patients with advanced GISTs because of its good efficacy and tolerability. Use of sunitinib and regorafenib as second- and the third-line agents, respectively, is supported by large randomized trials. There are, however, several agents that are potentially useful but have not yet been fully evaluated, such as sorafenib, masitinib, and ponatinib, and the novel approaches described warrant further study. In the authors' opinion, potentially effective novel agents may be investigated relatively early in patient populations with imatinib-refractory GIST, prior to treatment with sunitinib or regorafenib, as sunitinib and regorafenib are only moderately well tolerated and responses to them may remain relatively short lived.

Compliance with Ethical Standards No funding was received for this manuscript. SB has received research funding from Novartis and is to receive research funding from Ariad. SB has received consulting fees from Novartis, GlaxoSmithKline, BluePrint Medicines, Pfizer, and Bayer. $\mathrm{HJ}$ has received consulting fees from BluePrint Medicines and Ariad Pharmaceuticals.

Open Access This article is distributed under the terms of the Creative Commons Attribution-NonCommercial 4.0 International License (http://creativecommons.org/licenses/by-nc/4.0/), which permits any noncommercial use, distribution, and reproduction in any medium, provided you give appropriate credit to the original author(s) and the source, provide a link to the Creative Commons license, and indicate if changes were made.

\section{References}

1. Ducimetière F, Lurkin A, Ranchère-Vince D, Decouvelaere AV, Péoc'h M, Istier L, et al. Incidence of sarcoma histotypes and molecular subtypes in a prospective epidemiological study with central pathology review and molecular testing. PLoS One. 2011;6(8):e20294.

2. Kawanowa K, Sakuma Y, Sakurai S, Hishima T, Iwasaki Y, Saito K, et al. High incidence of microscopic gastrointestinal stromal tumors in the stomach. Hum Pathol. 2006;37(12):1527-35.

3. Agaimy A, Wünsch PH, Hofstaedter F, Blaszyk H, Rümmele P, Gaumann A, et al. Minute gastric sclerosing stromal tumors (GIST tumorlets) are common in adults and frequently show c-KIT mutations. Am J Surg Pathol. 2007;31(1):113-20.

4. Joensuu H, Vehtari A, Riihimäki J, Nishida T, Steigen SE, Brabec P, et al. Risk of recurrence of gastrointestinal stromal tumour after surgery: an analysis of pooled population-based cohorts. Lancet Oncol. 2012;13(3):265-74.

5. Dematteo RP, Lewis JJ, Leung D, Mudan SS, Woodruff JM, Brennan MF. Two hundred gastrointestinal stromal tumors: recurrence patterns and prognostic factors for survival. Ann Surg. 2000;231(1):51-8.

6. Hirota S, Isozaki K, Moriyama Y, Hashimoto K, Nishida T, Ishiguro $\mathrm{S}$, et al. Gain-of-function mutations of c-kit in human gastrointestinal stromal tumors. Science. 1998;279(5350):577-80.

7. Heinrich MC, Corless CL, Duensing A, McGreevey L, Chen CJ, Joseph N, et al. PDGFRA activating mutations in gastrointestinal stromal tumors. Science 2003(5607); 299:708-10.

8. Heinrich MC, Corless CL, Demetri GD, Blanke CD, von Mehren M, Joensuu $\mathrm{H}$, et al. Kinase mutations and imatinib response in patients with metastatic gastrointestinal stromal tumor. J Clin Oncol. 2003;21(23):4342-9.

9. DeMatteo RP, Ballman KV, Antonescu CR, Maki RG, Pisters PW, Demetri GD, et al. Adjuvant imatinib mesylate after resection of localised, primary gastrointestinal stromal tumour: a randomised, double-blind, placebo-controlled trial. Lancet. 2009;373(9669):1097-104.

10. Joensuu H, Eriksson M, Sundby Hall K, Hartmann JT, Pink D, Schütte J, et al. Twelve vs. 36 months of adjuvant imatinib as treatment of operable GIST with a high risk of recurrence: Final results of a randomized trial (SSGXVIII/AIO). JAMA. 2012;307(12):1265-72.

11. Demetri GD, von Mehren M, Blanke CD, Van den Abbeele AD, Eisenberg B, Roberts PJ, et al. Efficacy and safety of imatinib mesylate in advanced gastrointestinal stromal tumors. N Engl J Med. 2002;347(7):472-80.

12. Joensuu H, Hohenberger P, Corless CL. Gastrointestinal stromal tumour. Lancet. 2013;382(9896):973-83.

13. Verweij J, Casali PG, Zalcberg J, LeCesne A, Reichardt P, Blay $\mathrm{JY}$, et al. Progression-free survival in gastrointestinal stromal tumours with high-dose imatinib: randomised trial. Lancet. 2004;364(9440):1127-34.

14. Blanke CD, Demetri GD, von Mehren M, Heinrich MC, Eisenberg B, Fletcher JA, et al. Long-term results from a randomized phase II trial of standard- versus higher-dose imatinib mesylate for patients with unresectable or metastatic gastrointestinal stromal tumors expressing KIT. J Clin Oncol. 2008;26(4):620-5.

15. Debiec-Rychter M, Sciot R, Le Cesne A, Schlemmer M, Hohenberger P, van Oosterom AT, et al. KIT mutations and dose selection for imatinib in patients with advanced gastrointestinal stromal tumours. Eur J Cancer. 2006;42(8):1093-103. 
16. Cassier PA, Fumagilli E, Rutkowski P, Schöffski P, van Glabbeke M, Debiec-Rychter M, et al. Outcome of patients with platelet-derived growth factor receptor alpha-mutated gastrointestinal stromal tumors in the tyrosine kinase inhibitor era. Clin Cancer Res. 2012;18(16):4458-64.

17. Gastrointestinal stromal tumours: ESMO Clinical Practice Guidelines for diagnosis, treatment and follow-up. ESMO/ European Sarcoma Network Working Group. Ann Oncol. 2014;25(Suppl 3):iii21-6.

18. Blanke CD, Demetri GD, von Mehren M, Heinrich MC, Eisenberg B, Fletcher JA, et al. Long-term results from a randomized phase II trial of standard- versus higher-dose imatinib mesylate for patients with unresectable or metastatic gastrointestinal stromal tumors expressing KIT. J Clin Oncol. 2008;26(4):620-5.

19. Von Mehren M. Follow-up results after 9 years of the ongoing, phase II B2222 trial of imatinib mesylate in patients with metastatic or unresectable KIT+ gastrointestinal stromal tumors (GIST). J Clin Oncol. 2011;29(15S):609s (abstract \#10016).

20. Le Cesne A, Ray-Coquard I, Buy BN, Adenis A, Rios M, Bertucci F, et al. Discontinuation of imatinib in patients with advanced gastrointestinal stromal tumours after 3 years of treatment: an open-label multicentre randomised phase 3 trial. Lancet Oncol. 2010;11(10):942-9.

21. Kang YK, Ryu MH, Yoo C, Ryoo BY, Kim HJ, Lee JJ, et al. Resumption of imatinib to control metastatic or unresectable gastrointestinal stromal tumours after failure of imatinib and sunitinib (RIGHT): a randomised, placebo-controlled, phase 3 trial. Lancet Oncol. 2013;14(12):1175-82.

22. Demetri GD, van Oosterom AT, Garrett CR, Blackstein ME, Shah $\mathrm{MH}$, Verweij J, et al. Efficacy and safety of sunitinib in patients with advanced gastrointestinal stromal tumour after failure of imatinib: a randomised controlled trial. Lancet. 2006;368(9544):1329-38.

23. Sodergren SC, White A, Efficace F, Sprangers M, Fitzsimmons D, Bottomley A, et al. Systematic review of the side effects associated with tyrosine kinase inhibitors used in the treatment of gastrointestinal stromal tumours on behalf of the EORTC Quality of Life Group. Crit Rev Oncol Hematol. 2014;91(1):35-46.

24. George S, Blay JY, Casali PG, Le Cesne A, Stephenson P, Deprimo SE, et al. Clinical evaluation of continuous daily dosing of sunitinib malate in patients with advanced gastrointestinal stromal tumour after imatinib failure. Eur $\mathbf{J}$ Cancer. 2009;45(11):1959-68.

25. Demetri GD, Reichardt P, Kang YK, Blay JY, Rutkowski P, Gelderblom $\mathrm{H}$, et al. Efficacy and safety of regorafenib for advanced gastrointestinal stromal tumours after failure of imatinib and sunitinib (GRID): an international, multicentre, randomised, placebo-controlled, phase 3 trial. Lancet. 2013;381(9863):295-302.

26. Shah RR, Morganroth J, Shah DR. Hepatotoxicity of tyrosine kinase inhibitors: clinical and regulatory perspectives. Drug Saf. 2013;36(7):491-503.

27. Debiec-Rychter M, Cools J, Dumez H, Sciot R, Stul M, Mentens $\mathrm{N}$, et al. Mechanisms of resistance to imatinib mesylate in gastrointestinal stromal tumors and activity of the PKC412 inhibitor against imatinib-resistant mutants. Gastroenterology. 2005; 128(2):270-9.

28. Heinrich MC, Corless CL, Blanke CD, Demetri GD, Joensuu H, Roberts PJ, et al. Molecular correlates of imatinib resistance in gastrointestinal stromal tumors. J Clin Oncol. 2006;24(29):4764-74.

29. Gajiwala KS, Wu JC, Christensen J, Deshmukh GD, Diehl W, DiNitto JP, et al. KIT kinase mutants show unique mechanisms of drug resistance to imatinib and sunitinib in gastrointestinal stromal tumor patients. Proc Natl Acad Sci USA. 2009;106(5):1542-7.

30. Garner AP, Gozgit JM, Anjum R, Vodala S, Schrock A, Zhou T, et al. Ponatinib inhibits polyclonal drug-resistant KIT oncoproteins and shows therapeutic potential in heavily pretreated gastrointestinal stromal tumor (GIST) patients. Clin Cancer Res. 2014;20(22):5745-55.

31. Heinrich MC, Corless C, Liegl B, Fletcher CD, Raut CP, Donsky R, et al. Mechanisms of sunitinib malate resistance in gastrointestinal stromal tumors (GISTs). J Clin Oncol. 2007;25(18S):546s (abstract \#10006).

32. Wardelmann E, Thomas N, Merkelbach-Bruse S, Pauls K, Speidel N, Büttner R, et al. Acquired resistance to imatinib in gastrointestinal stromal tumours caused by multiple KIT mutations. Lancet Oncol. 2005;6(4):249-51.

33. Liegl B, Kepten I, Le C, Zhu M, Demetri GD, Heinrich MC, et al. Heterogeneity of kinase inhibitor resistance mechanisms in GIST. J Pathol. 2008;216(1):64-74.

34. Agaram NP, Wong GC, Guo T, Maki RG, Singer S, Dematteo RP, et al. Novel V600E BRAF mutations in imatinib-naive and imatinib-resistant gastrointestinal stromal tumors. Genes Chromosomes Cancer. 2008;47(10):853-9.

35. Serrano C, Wang Y, Marino-Enriquez A, Lee JC, Ravegnini G, Morgan JA, et al. KRAS and KIT gatekeeper mutations confer polyclonal primary imatinib resistance in GI stromal tumors: relevance of concomitant phosphatidylinositol 3-kinase/AKT dysregulation. J Clin Oncol. 2014 (Epub ahead of print).

36. Reichardt P, Blay JY, Gelderblom H, Schlemmer M, Demetri GD, Bui-Nguyen B, et al. Phase III study of nilotinib versus best supportive care with or without a TKI in patients with gastrointestinal stromal tumors resistant to or intolerant of imatinib and sunitinib. Ann Oncol. 2012;23(7):1680-7.

37. Blay JY. Phase III trial of nilotinib versus imatinib as first-line targeted therapy of advanced gastrointestinal stromal tumors (GIST). J Clin Oncol. 2013;31(15S):632s (abstract \#10501).

38. Montemurro M, Schöffski P, Reichardt P, Gelderblom H, Schütte J, Hartmann JT, et al. Nilotinib in the treatment of advanced gastrointestinal stromal tumours resistant to both imatinib and sunitinib. Eur J Cancer. 2009;45(13):2293-7.

39. Cauchi C, Somaiah N, Engstrom PF, Litwin S, Lopez M, Lee J, et al. Evaluation of nilotinib in advanced GIST previously treated with imatinib and sunitinib. Cancer Chemother Pharmacol. 2012;69(4):977-82.

40. Le Cesne A, Blay JY, Bui BN, Bouché O, Adenis A, Domont J, et al. Phase II study of oral masitinib mesilate in imatinib-naïve patients with locally advanced or metastatic gastro-intestinal stromal tumour (GIST). Eur J Cancer. 2010;46(8):1344-51.

41. Adenis A, Blay JY, Bui-Nguyen B, Bouché O, Bertucci F, Isambert $\mathrm{N}$, et al. Masitinib in advanced gastrointestinal stromal tumor (GIST) after failure of imatinib: a randomized controlled open-label trial. Ann Oncol. 2014;25(9):1762-9.

42. Heinrich MC, Marino-Enriquez A, Presnell A, Donsky RS, Griffith DJ, McKinley A, et al. Sorafenib inhibits many kinase mutations associated with drug-resistant gastrointestinal stromal tumors. Mol Cancer Ther. 2012;11(8):1770-80.

43. Montemurro M, Gelderblom H, Bitz U, Schütte J, Blay JY, Joensuu $\mathrm{H}$, et al. Sorafenib as third- or fourth-line treatment of advanced gastrointestinal stromal tumour and pretreatment including both imatinib and sunitinib, and nilotinib: A retrospective analysis. Eur J Cancer. 2013;49(5):1027-31.

44. Reichardt P, Montemurro M, Gelderbloom H, Blay J, Rutkowski $\mathrm{P}$, Bui B, et al. Sorafenib fourth-line treatment in imatinib-, sunitinib-, and nilotinib-resistant metastatic GIST: A retrospective analysis. J Clin Oncol. 2009;27:551s (abstract \#10564).

45. Kindler HL. Sorafenib in patients with imatinib and sunitinib resistant gastrointestinal stromal tumors (GIST): final results of 
a University of Chicago phase II consortium trial. J Clin Oncol. 2011;29(15S):607s (abstract \#10009).

46. Kang YK, Yoo C, Ryoo BY, Lee JJ, Tan E, Park I, et al. Phase II study of dovitinib in patients with metastatic and/or unresectable gastrointestinal stromal tumours after failure of imatinib and sunitinib. Br J Cancer. 2013;109(9):2309-15.

47. Joensuu H, Blay JY, Comandone A, Broto JM, Fumagalli E, Grignani E, et al. Phase 2 trial to evaluate the efficacy and safety of dovitinib in patients with gastrointestinal stromal tumor refractory and/or intolerant to imatinib. Ann Oncol. 2014;25(Suppl 4). doi:10.1093/annonc/mdu438.58 (abstract \#LBA46).

48. Kumar R, Knick VB, Rudolph SK, Johnson JH, Crosby RM, Crouthamel MC, et al. Pharmacokinetic-pharmacodynamic correlation from mouse to human with pazopanib, a multikinase angiogenesis inhibitor with potent antitumor and antiangiogenic activity. Mol Cancer Ther. 2007;6(7):2012-21.

49. Ganjoo KN, Villalobos VM, Kamaya A, Fisher GA, Butrynski JE, Morgan JA, et al. A multicenter phase II study of pazopanib in patients with advanced gastrointestinal stromal tumors (GIST) following failure of at least imatinib and sunitinib. Ann Oncol. 2014;25(1):236-40.

50. Blay J. Final results of the multicenter randomized phase II PAZOGIST trial evaluating the efficacy of pazopanib plus best supportive care vs BSC alone in resistant unresectable metastatic and/or locally advanced gastrointestinal stromal tumors (GIST). J Clin Oncol. 2015;33(15S):561s (abstract \#10506).

51. Cortes JE, Kantarjian H, Shah NP, Bixby D, Mauro MJ, Flinn I, et al. Ponatinib in refractory Philadelphia chromosome-positive leukemias. N Engl J Med. 2012;367(22):2075-88.

52. Heinrich MC, Von Mehren M, Demetri GD, Fletcher JA, Sun J, Hodgson G, et al. A phase 2 study of ponatinib in patients with advanced gastrointestinal stromal tumors (GIST) after failure of tyrosine kinase inhibitor (TKI) therapy: initial report. J Clin Oncol. 2014;32(15S):669s (abstract \#10506).

53. Shah NP, Talpaz M, Deininger MW, Mauro MJ, Flinn IW, Bixby $\mathrm{D}$, et al. Ponatinib in patients with refractory acute myeloid leukaemia: findings from a phase 1 study. $\mathrm{Br} \mathrm{J}$ Haematol. 2013;162(4):548-52.

54. Nokhara H, Yamamoto N, Nakamichi S, Wakus H, Yamada Y, Nguyen L, et al. A phase 1 study of cabozantinib in japanese patients with advanced solid tumors: anti-tumor activity in NSCLC and GIST. Ann Oncol 2013;24(suppl 9):ix48.

55. Leboulleux S, Bastholt L, Krause T, de la Fouchardiere C, Tennvall J, Awada A, et al. Vandetanib in locally advanced or metastatic differentiated thyroid cancer: a randomised, doubleblind, phase 2 trial. Lancet Oncol. 2012;13(9):897-905.

56. Zhou A, Zhang W, Chang C, Chen X, Zhong D, Qin Q, et al. Phase I study of the safety, pharmacokinetics and antitumor activity of famitinib. Cancer Chemother Pharmacol. 2013;72(5):1043-53.

57. Joensuu H, De Braud F, Grignagni G, De Pas T, Spitalieri G, Coco $\mathrm{P}$, et al. Vatalanib for metastatic gastrointestinal stromal tumour (GIST) resistant to imatinib: final results of a phase II study. Br J Cancer. 2011;104(11):1686-90.

58. Lindauer M, Hochhaus A. Dasatinib. Recent Results Cancer Res. 2010;184:83-102.

59. Montemurro M, Cioffi A, Domont J, Rutkowski P, Roth AD, von Moos R, et al. Long-term outcome of dasatinib first-line treatment in gastrointestinal stromal tumors: a multicenter two stage phase II trial SAKK 56/07. Ann Oncol. 2014;25(Suppl. 4):iv496 (abstract \#1418PD).

60. Trent JC. A phase II study of dasatinib for patients with imatinib-resistant gastrointestinal stromal tumor (GIST). J Clin Oncol. 2011;29(15S):606s (abstract \#10006).

61. Evans EK, Hodous BL, Gardino A, Zhu J, Shutes A, Davis A, et al. First selective KIT D816V inhibitor for patients with systemic mastocytosis. Blood. 2014;124(21):3217 (\#abstract 3217).

62. Heinrich MC, Griffith D, McKinley A, Patterson J, Presnell A, Ramachandran A, et al. Crenolanib inhibits the drug-resistant PDGFRA D842V mutation associated with imatinib-resistant gastrointestinal stromal tumors. Clin Cancer Res. 2012;18(16):4375-84.

63. Matro JM, Yu JQ, Heinrich MC, Ramachandran A, Ku N, von Mehren M. Correlation of PET/CT and CT RECIST response in GIST patient with PDGFRA D842V gene mutations treated with crenolanib. J Clin Oncol. 2014;32(15S):679s (abstract \#10546).

64. Collins R, Kantarjian HM, Levis MJ, Perl AE, Ramachandran A, Ravendi F, et al. Clinical activity of crenolanib in patients with D835 mutant FLT3-positive relapsed/refractory acute myeloid leukemia (AML). J Clin Oncol. 2014;32(15S)451s (abstract \#7027).

65. Workman P. Altered states: selectively drugging the Hsp90 cancer chaperone. Trends Mol Med. 2004;10(2):47-51.

66. Kamal A, Boehm MF, Burrows FJ. Therapeutic and diagnostic implications of Hsp90 activation. Trends Mol Med. 2004;10(6):283-90.

67. Bauer S, Yu LK, Demetri GD, Fletcher JA. Heat shock protein 90 inhibition in imatinib-resistant gastrointestinal stromal tumor. Cancer Res. 2006;66(18):9153-61.

68. Marino-Enriquez A, Ou WB, Cowley G, Luo B, Jonker AH, Mayeda $\mathrm{M}$, et al. Genome-wide functional screening identifies CDC37 as a crucial HSP90-cofactor for KIT oncogenic expression in gastrointestinal stromal tumors. Oncogene. 2014;33(14):1872-6.

69. Wagner AJ, Chugh R, Rosen LS, Morgan JA, George S, Gordon $\mathrm{M}$, et al. A phase I study of the HSP90 inhibitor retaspimycin hydrochloride (IPI-504) in patients with gastrointestinal stromal tumors or soft-tissue sarcomas. Clin Cancer Res. 2013;19(21):6020-9.

70. Demetri GD, Heinrich MC, Chmielowski, Morgan JA, George S, Bradley R, et al. An open-label phase II study of Hsp90 inhibitor ganetespib (STA-9090) in patients with metastatic and/ or unresectable GIST. J Clin Oncol. 2011;29(15S):607s (abstract \#10011).

71. Dickson MA, Okuno SH, Keohan ML, Maki RG, D'Adamo DR, Akhurst TJ, et al. Phase II study of the HSP90-inhibitor BIIB021 in gastrointestinal stromal tumors. Phase II study of the HSP90inhibitor BIIB021 in gastrointestinal stromal tumors. Ann Oncol. 2013;24(1):252-7.

72. Smyth T, Van LT, Curry JE, Rodriguez-Lopez AM, Wozniak A, Zhu M, et al. (2012). The HSP90 inhibitor, AT13387, is effective against imatinib-sensitive and -resistant gastrointestinal stromal tumor models. Mol Cancer Ther. 2012;11(8):1799-808.

73. Shapiro GI, Kwak E, Dezube BJ, Yule M, Ayrton J, Lyons J, et al. First-in-human phase I dose escalation study of a secondgeneration non-ansamycin HSP90 inhibitor, AT13387, in patients with advanced solid tumors. Clin Cancer Res. 2015;21(1):87-97.

74. Marks P, Rifkind RA, Richon VM, Breslow R, Miller T, Kelly WK. Histone deacetylases and cancer: causes and therapies. Nat Rev Cancer. 2001;1(3):194-202.

75. Johnstone RW. Histone-deacetylase inhibitors: novel drugs for the treatment of cancer. Nat Rev Drug Discov. 2001;1(4):287-99.

76. Kovacs JJ, Murphy PJ, Gaillard S, Zhao X, Wu JT, Nicchitta $\mathrm{CV}$, et al. HDAC6 regulates Hsp90 acetylation and chaperonedependent activation of glucocorticoid receptor. Mol Cell. 2005;18(5):601-7.

77. Muhlenberg T, Zhang Y, Wagner AJ, Grabellus F, Bradner J, Taeger G, et al. Inhibitors of deacetylases suppress oncogenic 
KIT signaling, acetylate HSP90, and induce apoptosis in gastrointestinal stromal tumors. Cancer Res. 2009;69(17):6941-50.

78. Floris G, Debiec-Rychter M, Sciot R, Stefan C, Fieuws S, Machiels K, et al. High efficacy of panobinostat towards human gastrointestinal stromal tumors in a xenograft mouse model. Clin Cancer Res. 2009;15(12):4066-76.

79. Bauer S, Hilger RA, Mühlenberg T, Grabellus F, Nagarajah J, Hoiczyk M, et al. Phase I study of panobinostat and imatinib in patients with treatment-refractory metastatic gastrointestinal stromal tumors. Br J Cancer. 2014;110(5):1155-62.

80. Bai Y, Bandara G, Ching Chan E, Maric I, Simakova O, Bandara SN, et al. Targeting the KIT activating switch control pocket: a novel mechanism to inhibit neoplastic mast cell proliferation and mast cell activation. Leukemia. 2013;27(2):278-85.

81. Mol CD, Dougan DR, Schneider TR, Skene RJ, Kraus ML, Scheibe DN, et al. Structural basis for the autoinhibition and STI-571 inhibition of c-Kit tyrosine kinase. (2004). J Biol Chem. 2004;279(30):31655-63.

82. Heinrich MC, Wise S, Hood M, Smith B, Kaufman M, Lu W, et al . In vitro activity of novel KIT/PDGFRA switch pocket kinase inhibitors against mutations associated with drug-resistant GI stromal tumors. J Clin Oncol. 2010;28(15S):699s (\#abstract 10007).

83. Bauer S, Duensing A, Demetri GD, Fletcher JA. KIT oncogenic signaling mechanisms in imatinib-resistant gastrointestinal stromal tumor: PI3-kinase/AKT is a crucial survival pathway. Oncogene. 2007;26(54):7560-8.

84. Chi P, Chen Y, Zhang L, Guo X, Wongvipat J, Shamu T, et al. ETV1 is a lineage survival factor that cooperates with KIT in gastrointestinal stromal tumours. Nature. 2010;467(7317):849-53.

85. Ran L, Sirota I, Cao Z, Murphy D, Chen Y, Shukla S, et al. Combined inhibition of MAP kinase and KIT signaling synergistically destabilizes ETV1 and suppresses GIST tumor growth. Cancer Discov. 2015;5(3):304-15.

86. Miranda C, Nucifora M, Molinari F, Conca E, Anania MC, Bordoni A, et al. KRAS and BRAF mutations predict primary resistance to imatinib in gastrointestinal stromal tumors. Clin Cancer Res. 2012;18(6):1769-76.

87. Andersson J, Sihto H, Meis-Kindblom JM, Joensuu H, Nupponen N, Kindblom LG. NF1-associated gastrointestinal stromal tumors have unique clinical, phenotypic, and genotypic characteristics. Am J Surg Pathol. 29(9):1170-6.

88. Daniels M, Lurkin I, Pauli R, Erbstosser E, Hildebrandt U, Hellwig K, et al. Spectrum of KIT/PDGFRA/BRAF mutations and phosphatidylinositol-3-kinase pathway gene alterations in gastrointestinal stromal tumors (GIST). Cancer Lett. 2011;312(1):43-54

89. Schoffski P, Reichardt P, Blay JY, Dumez H, Morgan JA, RayCoquard I, et al. A phase I-II study of everolimus (RAD001) in combination with imatinib in patients with imatinib-resistant gastrointestinal stromal tumors. Ann Oncol. 2010;21(10):1990-8.

90. Chi P. A phase Ib/II study of MEK162 (binimetinib) in combination with imatinib in patients with advanced gastrointestinal stromal tumor (GIST). J Clin Oncol. 2015;33(15S):561s (abstract \#10507).

91. Shoushtari AN, D'Angelo SP, Keohan ML, Dickson MA, Gounder MM, Abdullah AK, et al. Combined KIT and CTLA-4 blocade in patients with refractory GIST and other advanced sarcomas. J Clin Oncol. 2014;32(15S):673s (abstract\#10521).

92. Borg C, Terme M, Taieb J, Menard C, Flament C, Robert C, et al. Novel mode of action of c-kit tyrosine kinase inhibitors leading to NK cell-dependent antitumor effects. J Clin Invest. 2014;114(3):379-88.

93. Rusakiewicz S, Semeraro M, Sarabi M, Desbois M, Locher C, Mendez $\mathrm{R}$, et al. Immune infiltrates are prognostic factors in localized gastrointestinal stromal tumors. Cancer Res. 2014;73(12):3499-510.

94. Schneider-Stock R, Boltze C, Lasota J, Miettinen M, Peters B, Pross M, et al. High prognostic value of p16INK4 alterations in gastrointestinal stromal tumors. J Clin Oncol. 2003;21(9):1688-97.

95. Konecny GE, Winterhoff B, Kolarova T, Qi J, Manivong K, Dering J, et al. Expression of p16 and retinoblastoma determines response to CDK4/6 inhibition in ovarian cancer. Clin Cancer Res. 2011;17(6):1591-602.

96. Javidi-Sharifi N, Traer E, Martinez J, Gupta A, Taguchi T, Dunlap J, et al. Crosstalk between KIT and FGFR3 promotes gastrointestinal stromal tumor cell growth and drug resistance. Cancer Res. 2015;75(5):880-91.

97. Li F, Huynh H, Li X, Ruddy DA, Wang Y, Ong R, et al. FGFRmediated reactivation of MAPK signaling attenuates antitumor effects of imatinib in gastrointestinal stromal tumors. Cancer Discov. 2015.pii:CD-14-0763 (Epub ahead of print).

98. Henze J, Muhlenberg T, Simon S, Grabellus F, Rubin B, Taeger $\mathrm{G}$, et al. p53 modulation as a therapeutic strategy in gastrointestinal stromal tumors. PLoS One. 2012;7(5):e37776.

99. Blanke CD, Demetri GD, Von Mehren M, Heinrich MC, Eisenberg B, Fletcher JA, et al. Long-term results from a randomized phase II trial of standard- versus higher-dose imatinib mesylate for patients with unresectable or metastatic gastrointestinal stromal tumors expressing KIT. J Clin Oncol. 2008;26(4):620-5.

100. Bauer S, Rutkowski P, Hohenberger P, Miceli R, Fumagalli E, Siedlecki JA, et al. Long-term follow-up of patients with GIST undergoing metastasectomy in the era of imatinib-analysis of prognostic factors (EORTC-STBSG collaborative study). Eur J Surg Oncol. 2014;40(4):412-9. 